\title{
Safe Affordable Fission Engine (SAFE 30) module conductivity test thermal model correlation.
}

\author{
Jose Roman, NASA/Marshall Space Flight Center, Huntsville, AL
}

\begin{abstract}
Two SAFE 30 modules were tested to determinate the thermal conductivity efficiency of the tri-cusps filled between the heat pipe and the heater cores. The modules consisted of four one-inch diameter tubes with heaters joined to an empty l" diam. tube. The test was conducted on a vacuum chamber with 4 configurations: tri-cusps filled with and without radiation shielding and non-filled tri-cusps with and without radiation shielding. The tri-cusps material helps the bonding of the heat pipe to the four electric heater cores, filling the gap between the pipes. The baseline configuration is a brazed joint between the pipe. The test consisted of controlling the power applied to the heaters until a set surface temperature is reach. The temperatures varied between a max. of $800 \mathrm{C}^{\circ}$ to $500^{\circ}$. Test data, input energy and chamber surface temperature from each individual test, was used as boundary conditions for the model. Nodes located on the same location as the test thermocouples were plotted again test data to determinate the accuracy of the analysis. The unknown $n$ variables on the analysis are the radiation emissivity of the pipe and chamber and the radiation view factor between the module and the chamber. A correlation was determined using a parametric analysis varying the surface emissivity and view factor until a good match was reach.
\end{abstract}

\section{INTRODUCTION}

The Safe Affordable Fission Engine (VanDyke,2000), an experimental fission rocket engine is being developed at the Advanced Propulsion Center at the Marshall Space Flight Center. The engine core is composed of a group of modules joined together. Each module is made of four one-inch diameter (1.in. OD.) heated tubes joined to a oneinch diameter heat pipe. For safety and simplification reasons, electric heaters simulate the fission fuel rods during testing. Two SAFE modules with a simulated heat pipe, empty tube, were tested to determine the heat transfer efficiency of two types of braze joints between the heat pipe and the heater tubes. In the "Open" configuration, the interstitial region between the tubes is not filled and the tubes are brazed together along the line of contact between the tubes. In the "Tri-cusp" configuration, the interstitial void is filled with braze. The tests were conducted in a vacuum chamber at the Marshall Space Flight Center Advance Propulsion Laboratory B. Two thermal models were created with each configuration, with and without the tri-cusp filled material and with and without foil around the modules. The tri-cusp material helps the bonding of the heat pipe to the four electric heater tubes, filling the gap between the pipes. The baseline is the open configuration - a brazed joint between the pipe. Test data was used to correlate the models and to quantify the heat transfer capability of the tri-cusp material. Tests of modules with a heat pipe have been conducted but correlation and thermal analysis has not been finished at this time.

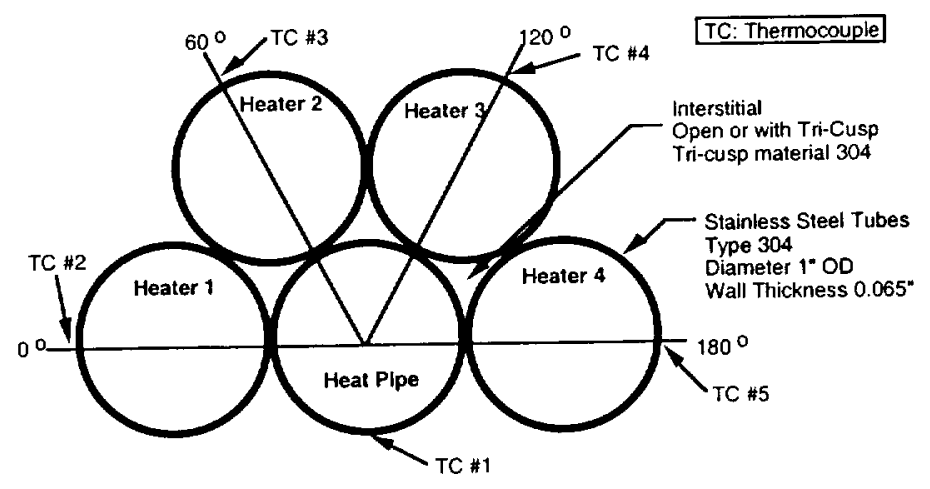

FIGURE 1. Test Module Configuration. 


\section{TEST DESCRIPTION}

The test consisted of controlling the power applied to the heaters $(500-2800 \mathrm{~W}$ per module) until a set surface temperature was reached. Vacuum conditions limited the module to radiative cooling only. The surface temperatures of the module varied between 500 to $800 \mathrm{C}^{\circ}$. Tube surface temperatures were recorded for each test. Figure 1 shows a typical test article and the thermocouple locations. Four configurations of the two modules were tested. Table 1 shows the test matrix configuration. The foil shield was used to hold in more heat by reflecting the radiation back onto the module.

TABLE 1. Test Matrix Configuration

\begin{tabular}{cccl}
\hline test \# & Joint Configuration & \multicolumn{1}{c}{ Foil } & \multicolumn{1}{l}{ Voltages } \\
\hline I & tri-cusp (filled) & no shield & $0-130,110,90,70$ \\
2 & tri-cusp (filled) & shield & $0-130,120,100,80,60$ \\
2A & tri-cusp (filled) & shield & $0-140,120,100,80$ \\
2B & tri-cusp (filled) & shield & $0-60,80,100$ \\
2C & tri-cusp (filled) & shield & $0-140,100$ \\
3 & open (not filled) & shield & $0-140,120,100,80,60$ \\
3A & open (not filled) & shield & $8-140,120,100,80,140$ \\
3B & open (not filled) & shield & $60,80,100$ \\
2D & tri-cusp (filled) & shield & $7-140,80,140$ \\
1A & tri-cusp (filled) & no shield & Emissivity Test \\
IB & tri-cusp (filled) & no shield & $5-140,120,100,80,140$ \\
IC & tri-cusp (filled) & no shield & $60,80,100,120$ \\
4 & open (not filled) & no shield &
\end{tabular}

\section{THERMAL ANALYSIS}

Two dimensional SINDA transient models were use for the thermal analysis. The models represented each of the two configurations tested - open and tri-cusp. Test data were used to fix the boundary conditions for each test configuration. Heater power, chamber inner wall temperature and foil surface temperatures from each test were input on the model as boundary conditions as well. Temperature dependent material properties (Rocketdyne) were used which included thermal conductivity, heat capacitance and density. Surface emissivity was calculated using test data. Figures 2 and 3 shows the two FEM meshes used in the analysis.

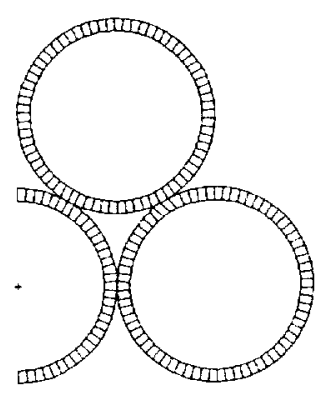

FIGURE 2. Open Configuration

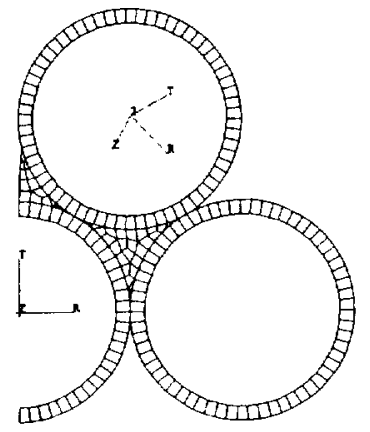

FIGURE 3. Tr-icusp Configuration

The used of the vacuum chamber caused the modules to be cooled by radiation heat transfer only. This condition restricted the analysis results to be strongly dependent of the module tubes surface condition and finish. On the open configuration model radiation is allowed within the gap between the tubes. 


\section{MODEL CORRELATION}

Tests results from tests 1B, 2C, 3 and 4, such as input energy and chamber surface temperature from each individual test, was used as boundary conditions for the models. Model node temperatures at the same location as the test thermocouples were plotted again test data to determine the accuracy of the analysis, as shown in Figures 4, 5, 6 and 7. The analysis has a maximum error of $9.4 \%$ (a deviation of $73 \mathrm{C}^{\circ}$ at steady state maximum power conditions) from test data. The unknown variables in the analysis are the radiation emissivity of the pipe and chamber and the radiation view factor between the module and the chamber. A correlation was determined using a parametric analysis varying the surface emissivity and view factor until a good match was reached.

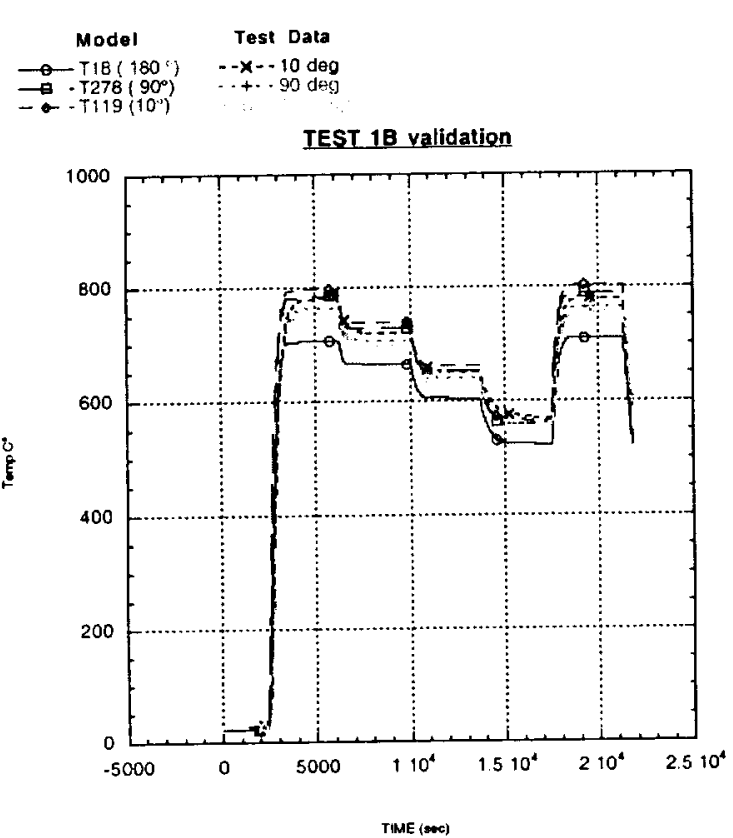

FIGURE 4. Test 1B Tri-cusp/ no Foil

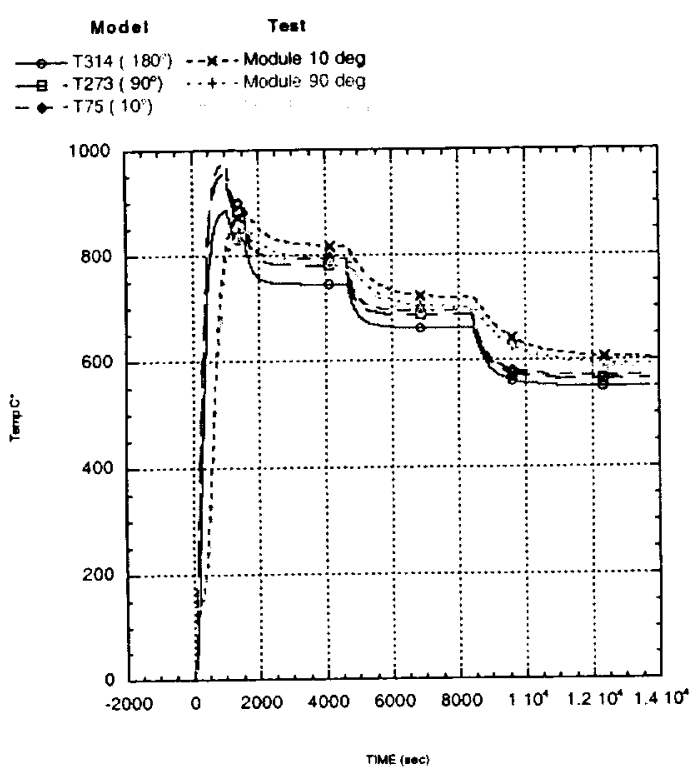

FIGURE 6. Test 3 Open /Foil

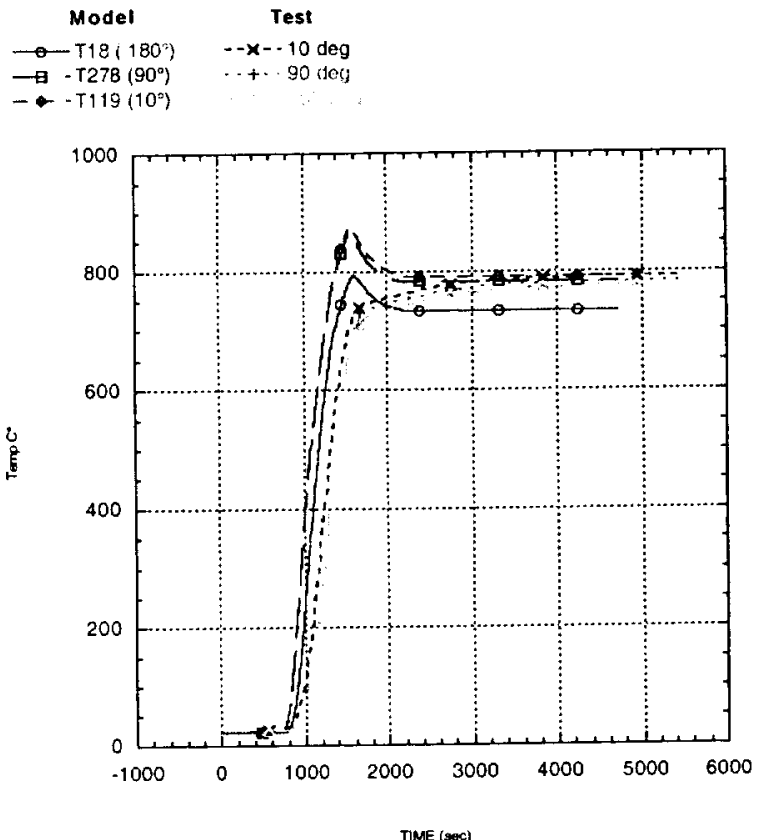

FIGURE 5. Test $2 \mathrm{C}$ Tri-cusp /Foil
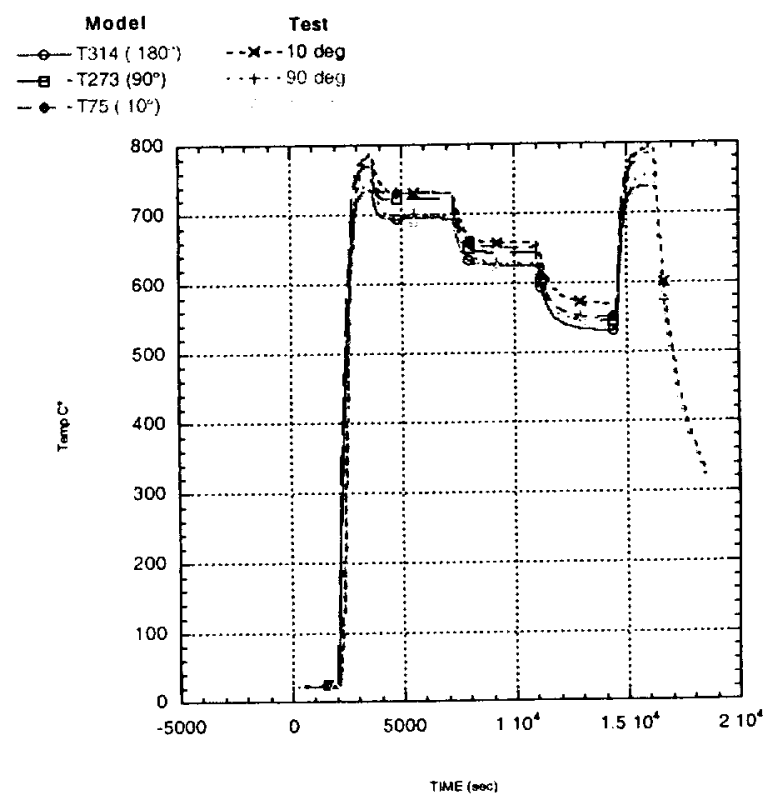

FIGURE 7. Test 4 Open/ no Foil 


\section{CONCLUSIONS}

A good correlation with the test data for all test conditions was obtained. The model response was sensitive to the surface emissivity of the module. This emissivity varied, from .98 to .86 calculated using test data, during testing due to changes in the surface oxidation during the power cycles.

The used of the tri-cusp to joint the pipes increased by $41 \%$ the ability to transfer heat between the heated pipes and the heat pipe simulator. This increase was measured using the relation of the total heat transfer from the heaters to an effective thermal conductivity by radiation, Equation 1, compared to the thermal conductivity of the tri-cusp material. Equation 2 shows this relation

$$
q=k_{\text {eff }} A / L\left(T_{\text {heated tube }}-T_{\text {heat pipe }}\right)
$$

For the solid tri-cusp $\mathrm{k}_{\mathrm{ss}}=$ conductivity of stainless steel at steady state condition $\left(22.41 \mathrm{~W} / \mathrm{m}^{\circ}{ }^{\circ} \mathrm{C}\right)$ and for the modules $\mathrm{A} / \mathrm{L}=.0126 \mathrm{~m}$

From analysis:

$\left(\mathrm{T}_{\text {heated tube }}-\mathrm{T}_{\text {heat pipe }}\right)=116.9^{\circ} \mathrm{C} \quad$ at $\quad \mathrm{q} / \mathrm{A}=33 \mathrm{~W}$

Using same heat transfer rate lets calculated for radiation

$$
\mathrm{q}=33 \mathrm{~W}=\mathrm{k}_{\text {eff }}\left(\mathrm{T}_{\text {heated tube }}-\mathrm{T}_{\text {heat pipe }}\right)
$$

Keeping $T_{\text {heated tube }}$ the same and solving the energy balance using radiation with emissivity equal to 1 .

$$
\left(T_{\text {heated tube }}-T_{\text {heat pipe }}\right)=176.1^{\circ} \mathrm{C} \quad \text { and } \quad k_{\text {eff }}=13.66 \mathrm{~W} /\left(\mathrm{m}-{ }^{\circ} \mathrm{C}\right) \text { therefor }
$$

Thermal conductivity efficiency gain $=1-\left(k_{\mathrm{eff}} / \mathrm{k}_{\mathrm{ss}}\right)$

$$
\begin{aligned}
& =1-13.66 / 22.41 \\
& =41 \%
\end{aligned}
$$

The used of the tri-cusp gained an increased of $41 \%$ of the effective conductivity of radiation and increase of tube surface temperature of $59^{\circ} \mathrm{C}$.

The lessons learned on this analysis are going to be used on the other configurations including heat pipe modules and SAFE 30 core. A model correlation with the heat pipe module (underway at this time) will be completed. A more accurate analysis of the SAFE30 core will be reached with the use of the correlated model presented on this paper and the heat pipe model correlation.

\section{REFERENCES}

VanDyke M., Houts M, and et al, "First Generation Least Expensive Approach to Fission Testing Results", 30th

AIAA/ASME/SAE/ASEE, Joint Propulsion Conference, July 16-19, Huntsville, AL, paper. AIAA 2000-5356

Material Properties Manual, Vol. 1, Rockwell International, Rocketdyne Division, section 2204. 